\title{
Analisis Tourist Experience Terhadap Revisit Intention pada Objek Wisata Air Panas Se Kabupaten Garut
}

\author{
Rahyuniati Setiawan ${ }^{1}$. Deri Alan Kurniawan ${ }^{2}$ \\ Fakultas Ekonomi, Jurusan Management, Universitas Garut \\ Jalan Samarang, No. 52 A, Tlp. 08112124600, Fax. (0262) 544217 Garut-44151 \\ rahyu@uniga.ac.id ${ }^{1}$
}

\begin{abstract}
Abstrak- Kepuasan wisatawan terbentuk karena adanya pengalaman yang dirasakan oleh konsumen setelah menggunakan produk dan jasa yang dimaksud, sehingga menimbulkan nilai yang baik. Reputasi daerah sebagai destinasi wisata telah merangsang pertumbuhan pasar sehingga pemahaman tentang revisit intention untuk wisatawan penting bagi pengelola pengembangan wisata agar strategi pemasaran tepat sasaran dan efektif. Keberagaman objek wisata dan daya tarik wisata alam yang melimpah seperti seni budaya, wisata sejarah, wisata belanja serta kerajinan asli daerah mempunyai dampak yang besar untuk memberikan pengalaman terbaik bagi wisatawan sehingga dapat berdampak pada revisit intention. Pariwisata pada dasarnya menciptakan pengalaman bagi wisatawan atau tourist experience. Adapun tujuan penelitian dari analisis tourist experience terhadap revisit intention pada objek wisata pemandian air panas se Kabupaten Garut adalah: (1) untuk memperoleh temuan mengenai gambaran tourist experience pada objek wisata pemandian air panas se Kabupaten Garut (2) untuk memperoleh temuan mengenai tingkat revisit intention pada objek wisata pemandian air panas se Kabupaten Garut, (3) untuk memperoleh temuan mengenai pengaruh tourist experience terhadap revisit intention pada objek wisata pemandian air panas se Kabupaten Garut. Sedangkan desain riset yang akan digunakan adalah systematic random sampling dan jenis sampling yang digunakan adalah populasi bergerak (mobile sampling).
\end{abstract}

Kata Kunci- tourist experience, revisit intention

Abstract - Tourist satisfaction is formed because of the experience felt by consumers after using the proposed products and services, giving rise to good value. The reputation of the region as a tourist destination must increase growth of the purpose of return visits for tourists is important for tourism managers so that marketing strategies are on target and effective. The diversity of tourist objects and and abundant natural tourist attractions such as cultural arts, historical tourism, shopping tourism and native crafts of the region have great importance to provide the best tourist experience for tourists so that it can be seen in the intention to re-visit. Tours on the experience for tourists or tourists. The research objectives of the analysis of tourist experiences on the intention to revisit hot air baths in Garut, consist of : (1) to obtain findings about the experience of tourists in hot air baths in Garut (2) to look for findings on the purpose of a return visit in hot air bathing attractions in Garut (3) to get a visit experience related to the intention to re-visit hot spring bathing attractions in Garut. While the research design that will be used is a systematic random sample and the type of sample used is a mobile population. By determining the respondent, determine the place as a check point, determine the time, and then ask for approval to be given a questionnaire. Questionnaires were measured using a Likert scale (ranking summary) each scale had 7 categories.

Keyword- tourist experience, revisit intention

\section{PENDAHULUAN}

Meningkatkan revisit intention telah menjadi isu terkini dalam bidang pemasaran di industri jasa dan merupakan konsep yang penting dalam memahami produk dan jasa sehingga menjadi fokus utama dalam penelitian pemasaran (Bigné et al, 2009 ; Bodet 2008) dalam jurnal (J. V Chen, Htaik, Hiele, \& Chen, 2016) Revisit intention merupakan salah satu kunci manajerial yang menguntungkan, bahkan revisit intention adalah salah satu komponen kunci dari wisatawan setia sehingga berdampak kepada keuntungan jangka panjang. Dalam penelitian Pariwisata, revisit intention teridentifikasi ketika wisatawan ingin datang kembali ke destinasi tersebut sehingga konstruk revisit intention telah dikonseptualisasikan sebagai keputusan wisatawan terhadap kunjungan kembali ke destinasi yang sama. Revisit intention pertama kali dipengaruhi oleh kinerja destinasi secara keseluruhan, revisit intention dipengaruhi sebagian besar oleh upaya promosi untuk mengingat pengalaman yang positif wisatawan dengan menyebarkan informasi tentang atraksi baru (Opperman 2000 dalam jurnal Um, Chon, \& Ro, 2006).

Wisata-wisata alam yang terdapat dikabupaten Garut antara lain Cipanas, situ cangkuang, situ bagendit, pantai sayang heulang, pantai santolo, pantai rancabuaya, Pantai Manalusu, Pantai Gunung Geder, Pantai Karang Paranje, Kampung Dukuh, Kawah Papandayan, Curug Orok, Curug Citiis, dan Curug Sanghyang Taraje, serta memiliki kesenian kesenian seperti Pencak Ular, Debus, Surak Ibra, Lais dan Raja Dogar. Selain wisata dan kesenian Kabupaten Garut juga memiliki beberapa kerajinan seperti Kerajinan Kulit, Akar Wangi, Batik Garutan dan Miniatur Domba Garut. 
Tabel 1.1 Data Kunjungan Ke Objek Wisata di Kabupaten Garut Tahun 2018

\begin{tabular}{clccc}
\hline No & \multicolumn{1}{c}{ Nama } & \multicolumn{2}{c}{ Jumlah } & Total \\
\cline { 3 - 4 } & & Wisman & Wisnus & \\
\hline 1. & Pantai Santolo & 150 & 2.735 .490 & 2.735 .640 \\
\hline 2. & $\begin{array}{l}\text { Pantai Sayang } \\
\text { Heulang }\end{array}$ & 97 & 2.535 .602 & 2.535 .699 \\
\hline 3. & Cipanas & 140 & 2.484 .068 & 2.484 .208 \\
\hline 4. & Pantai & 161 & 2.217 .229 & 2.217 .390 \\
& Rancabuaya & & & \\
\hline 5. & $\begin{array}{l}\text { Twa Kawah } \\
\text { Papandayan }\end{array}$ & 1038 & 1.866 .311 & 1.867 .349 \\
& & & \\
\hline
\end{tabular}

Sumber : Dinas Kebudayaan dan Pariwisata Kabupaten Garut 2019

Berdasarkan data dapat diketahui bahwa Objek Wisata Cipanas merupakan salah satu tempat wisata paling banyak pengunjungnya diantara 31 tempat pariwisata yang ada di Kabupaten Garut. Objek Wisata Cipanas berada di posisi ke-3 dengan jumlah pengunjungnya sebanyak 2.535 .699 pengunjung. Hal ini menunjukan Objek Wisata Cipanas mempunyai daya tarik wisata unggulan sebagai Destinasi wisata air panas yang telah merangsang pertumbuhan pasar wisata air panas.

\begin{tabular}{ccccc}
\hline Tahun & $\begin{array}{c}\text { Mancan } \\
\text { egara }\end{array}$ & Nusantara & Jumlah & Presentase \\
\hline 2013 & 610 & 405.492 & 406.102 & - \\
\hline 2014 & 428 & 320.521 & 320.949 & $-26,5 \%$ \\
\hline 2015 & 830 & 545.476 & 546.306 & $41,3 \%$ \\
\hline 2016 & 854 & 589.414 & 590.268 & $7,4 \%$ \\
\hline 2017 & 937 & 646.445 & 647.382 & $8,8 \%$ \\
\hline 2018 & 834 & 628.915 & 629.749 & $-2,8 \%$ \\
\hline
\end{tabular}

Tabel 1.2 Data Kunjungan Wisatawan ke Cipanas Garut Tahun 2013-2018

Sumber: Dinas Kebudayaan dan Pariwisata Kabupaten Garut 2019

Berdasarkan data tabel 1.2 Data Kunjungan Wisatawan ke Cipanas Garut mengalami fluktuasi dari tahun 2013 hingga tahun 2018. Semakin tingginya pertumbuhan wisata air panas bukan suatu jaminan tingkat loyalitas wisatawan untuk kembali berkunjung semakin tinggi.

Berdasarkan latar belakang penelitian yang telah diuraikan, revisit intention wisatawan menjadi kajian yang penting untuk keberhasilan objek wisata agar dapat maju dan berkembang. Revisit intention jika diabaikan akan menurunkan keputusan pembelian wisatawan akan produknya Setiap perusahaan didirikan dengan tujuan tertentu sehingga dapat tetap hidup dan berkembang.

\section{KAJIAN PUSTAKA}

Pentingnya revisit intention berasal dari quality experience dari tempat destinasi tersebut. Revisit Intention ke destinasi akan dipengaruhi oleh citra destination itu sendiri, serta upaya promosi dan penyebaran pemasaran dari objek destinasi sehingga citra destinasi merupakan salah satu faktor yang mempengaruhi revisit intention. Faktor lanjut yang terlibat dalam evaluasi revisit intention mencakup intention to recommended dan word of mouth yang positif. Revisit intention pengunjung ke destination akan terpengaruhi oleh penampilan destinasi. Revisit intention adalah niat kembali yang merujuk kepada penilaian subjektif individu pada tindakan masa depan atau tindakan spesifik atau perilaku konsumen dapat menerapkan mengenai sikap target.

Selain itu, perilaku wisatawan memiliki peranan penting bagi sebuah perusahaan untuk mengetahui kebutuhan dan keinginan wisatawan (Reid dan Bojanic, 2009). Tourist experience merupakan hasil interaksi dari destinasi, sistem pariwisata, masyarakat dan wisatawan yang lain. Tiga tahap yang saling mempengaruhi satu sama lain untuk konstruk dan bentuk pengalaman pariwisata yaitu pra kunjungan, selama kunjungan, dan tahap paska kunjungan.

Dimensi tourist experience dibagi menjadi empat, yaitu, entertainment, educational, esthetic, and escape, tergantung pada bentuk keterlibatan konsumen dalam pengalamannya.

\begin{tabular}{|l|}
\hline \multicolumn{1}{c}{ Tourist } \\
Experience \\
- Entertainment \\
- Educational \\
- Esthetic \\
- Escape
\end{tabular}$\longrightarrow \longrightarrow$\begin{tabular}{l}
\multicolumn{1}{c|}{ Revisit } \\
Intention \\
- Repeat Purchase \\
- Repeat Visits \\
- Recommendation \\
- Escape \\
- Remaks
\end{tabular}

Gambar 1 Paradigma Pengaruh Tourist Experience Terhadap Revisit Intention Wisatawan Pemandian Air Panas Garut

\section{METODE PENELITIAN}

Metode penelitian yang digunakan adalah metode penelitian deskriptif dan verifikatif. Metode ini menggambarkan objek penelitian berdasarkan fakta yang ada dan sedang berlangsung, dengan cara mengumpulkan, menyusun dan menjelaskan data yang diperlukan untuk kemudian di analisis sesuai teori yang ada. Sedangkan sumber data dalam penelitian ini 
dapat dibedakan menjadi dua, yaitu data primer dan data sekunder. Data primer yang diperoleh peneliti yaitu data berupa data kunjungan wisatawan dari Dinas Pariwisata dan Kebudayaan Kabupaten Garut Tahun 2013-2018 dan beberapa studi literatur. Peneliti juga mendapatkan data sekunder mengenai hal-hal yang berhubungan dengan penelitian ini dan peneliti melakukan observasi secara langsung ke destinasi wisata air panas se Kabupaten Garut.

Metode yang digunakan dalam teknik pengumpulan data berupa: kuisioner, berisi pertanyaan mengenai identitas dan pengalaman responden, penilaian responden mengenai tourist experience objek wisata air panas se Kabupaten Garut dan revisit intention.

Skala pengukuran Variabel Penelitian dilakukan dengan skala likert (summated Rating). Masing-masing skala mempunyai 5 kategori, yang berada diantara "sangat tidak setuju" sampai dengan "sangat setuju". Setelah itu, peneliti melakukan analisis verifikatif dalam penelitian ini menggunakan analisis jalur (path analysis) dan dalam penelitian kuantitatif analisis data dilakukan setelah data seluruh responden terkumpul. Pada penelitian ini menggunakan data interval. Data penelitian yang telah berskala interval selanjutnya akan ditentukan pasangan data variabel independent dengan variabel dependent serta akan ditentukan persamaan yang berlaku untuk pasangan-pasangan tersebut. Kemudian analisis jalur (path analysis) merupakan satu analisis peramalan nilai pengaruh satu variabel bebas (X) atau lebih terhadap variabel terikat (Y). Menerjemahkan ke dalam beberapa sub hipotesis yang menyatakan pengaruh sub variabel independen yang paling dominan terhadap variabel dependen.

\section{HASIL DAN PEMBAHASAN}

Penelitian ini dilakukan di Kabupdaten Garut, Jawa Barat yang memiliki topografi yang lengkap, terdiri dari pantai, gunung, danau, sungai, dan daratan, dengan ketinggian antara 0-2.839 meter di atas permukaan laut. Reka bentuk alamnya bervariasi, antara dataran yang landai dan dataran yang berlereng cukup curam tersedia dengan proporsi yang cukup memadai sehingga pemanfaatan lahan juga bisa sangat bervariasi.

Kabupaten Garut terdiri dari objek wisata alam, budaya, dan objek wisata minat khusus. Objek wisata yang dijadikan sample dalam penelitian ini adalah wisata alam yang merupakan ciri khas tersendiri dari kabupaten Garut dan menjadi salah satu objek pariwisata unggulan yang mampu meningkatkan omset terbesar dari sektor pariwisata Kabupaten Garut. Serta objek wisata yang menjadi unggulan Pemerintah Kabupaten Garut yaitu Cipanas yang merupakan salah satu objek wisata yang sangat eksotik.

Sample yang diambil dalam penelitian ini hanya 10 objek wisata pemandian air panas namun sumber data diperoleh dari responden yaitu pengunjung sebanyak 400 orang yang disebar dalam 10 objek wisata se Kabupaten Garut.

Tabel 4,1 Data Responden Berdasarkan Jenis

\begin{tabular}{ccc}
\multicolumn{3}{c}{ Kelamin } \\
\hline Pernyataan & Frekuensi & $\%$ \\
\hline Laki-Laki & 184 & 46 \\
\hline Perempuan & 216 & 51 \\
\hline Jumlah & 400 & 100
\end{tabular}

Sumber: Data diolah dari Angket Penelitian

Pengunjung yang berjenis kelamin laki-laki maupun perempuan berjumlah 400 orang. Jadi dapat terlihat berdasarkan pengelompokkan responden yang dibedakan menurut jenis kelamin, diantara keduanya tidak terlalu signifikan, sehingga dapat disebutkan bahwa pengujung pemandian air panas ini relatif.

\begin{tabular}{ccc}
\multicolumn{2}{c}{ Tabel 4,2 Data Usia Responden } \\
\hline Pernyataan & Frekuensi & $\%$ \\
\hline$<19$ & 78 & 19,5 \\
\hline $20-40$ & 157 & 39,2 \\
\hline $41-61$ & 134 & 33,5 \\
\hline$>62$ & 31 & 7,8 \\
\hline Jumlah & 400 & 100
\end{tabular}

Sumber : Data diolah dari Angket Penelitian

Golongan usia responden yang terbanyak mengunjungi pemandian air panas adalah 20-40 tahun dengan total 157 responden $(39,2 \%)$.

Tabel 4,3 Data Tingkat Pendidikan Responden

\begin{tabular}{ccc}
\hline Pernyataan & Frekuensi & \% \\
\hline SD & 47 & 12 \\
\hline SMP & 110 & 27 \\
\hline SMA & 135 & 34 \\
\hline Perguruan Tinggi & 108 & 27 \\
\hline Jumlah & 235 & 100
\end{tabular}

Sumber : Data diolah dari Angket Penelitian

Golongan tingkat pendidikan responden paling banyak adalah pada kalangan pelajar SMA sebanyak 135 responden (34\%).

Tabel 4,4 Data Mata Pencaharian Responden

\begin{tabular}{ccc}
\hline Pernyataan & Frekuensi & \% \\
\hline Pelajar/ Mahasiswa & 168 & 42 \\
\hline
\end{tabular}




\begin{tabular}{ccc}
\hline Pegawai Swasta & 103 & 26 \\
\hline Wiraswasta & 55 & 14 \\
\hline Pegawai Negeri & 34 & 8 \\
\hline Lainnya & 40 & 10 \\
\hline Jumlah & 400 & 100
\end{tabular}

Sumber : Data diolah dari Angket Penelitian Sebagian besar mata pencaharian responden adalah pelajar/mahasiswa yaitu sebanyak 168 responden atau sebanyak $(42 \%)$.

Tabel 4,5 Data Tingkat Pendapatan Responden

\begin{tabular}{ccc}
\hline Pernyataan & Frekuensi & $\%$ \\
\hline <Rp. 1.000.000 & 111 & 28 \\
\hline Rp. 1.000.000-Rp. 2.500.000 & 148 & 37 \\
\hline Rp. 2.600.000 - Rp. 4.000.000 & 98 & 25 \\
\hline Rp. 4.100.000 - Rp 5.500.000 & 30 & 7 \\
\hline >Rp 5.500.000 & 13 & 3 \\
\hline Jumlah & 400 & 100 \\
\hline
\end{tabular}

Sumber : Data diolah dari Angket Penelitian

Sebagian besar pendapatan responden adalah pada rentang Rp. 1000.000 - Rp.2.500.000, hal ini disebabkan sebagian besar yang mengisi kuesioner adalah kalangan pelajar dan mahasiswa.

Selain itu, terdapat korelasi antar variabel independent, yaitu Korelasi antara Entertainment Experience (X1) dengan Education Experience (X2), Escape Experience (X3), dan Esthetic Experience (X4) sebesar 0,501 artinya korelasi kuat, karena dengan nilai Signifikan sebesar $0,000<0,05$ yang artinya hubungan ke dua variabel tersebut kuat. Sedangkan Korelasi antara Education Experience (X2) dengan Education Experience (X3) sebesar 0,485 artinya korelasi kuat, dan korelasi antara Education Experience (X2) dengan Esthetic Experience (X4) sebesar 0,0,256 artinya korelasi kuat, karena dengan nilai Signifikan sebesar $0,000<0,05$ yang artinya hubungan ke dua variabel tersebut kuat.

Korelasi antara Repeat Purchase (Y1) dengan Repeat Visits (Y2) sebesar 0,437, korelasi antara Repeat Purchase (Y1) dengan Recommendation (Y3) sebesar 0,433 dan korelasi antara Repeat Visits (Y2) dengan Recommendation (Y3) sebesar 0,543 artinya korelasi kuat, karena dengan nilai Signifikan sebesar $0,000<0,05$ yang artinya hubungan ke dua variabel tersebut kuat.

Tabel 4,6 Modal Summary Variabel Independent Pada Repeat Purchase

\begin{tabular}{|l|r|r|r|r|}
\hline Model & $\mathrm{R}$ & $\mathrm{R}$ Square & \multicolumn{1}{|c|}{$\begin{array}{c}\text { Adjusted } \mathrm{R} \\
\text { Square }\end{array}$} & $\begin{array}{c}\text { Std. Error of the } \\
\text { Estimate }\end{array}$ \\
\hline 1 &, $505^{\mathrm{a}}$ &, 255 &, 248 & 2,044 \\
\hline
\end{tabular}

Predictors: (Constant), Esthetic Experience X4, Education Experience X2, Escape Experience X3, Entertainment Experience X1

Nilai R Square sebesar 0,255 sehingga dapat diartikan bahwa variasi Repeat Purchase dapat dijelaskan oleh variasi Entertainment Experience, Escape Experience, Education Experience dan Esthetic Experience sebesar 25,5\% dan sisanya sebesar $74,5 \%$ ditentukan atau dapat dijelaskan oleh variasi variabel lain yang tidak di teliti.

Tabel 4,7 Modal Summary Variabel Independent Pada Repeat Visit

\begin{tabular}{|l|r|r|r|r|}
\hline Model & $R$ & $R$ Square & \multicolumn{1}{|c|}{$\begin{array}{c}\text { Adjusted } R \\
\text { Square }\end{array}$} & $\begin{array}{c}\text { Std. Error of the } \\
\text { Estimate }\end{array}$ \\
\hline 1 &, $591^{\mathrm{a}}$ &, 350 &, 343 & 1,787 \\
\hline
\end{tabular}

Predictors: (Constant), Esthetic Experience X4, Education Experience X2, Escape Experience X3, Entertainment Experience X1.

Tabel 4,8 Modal Summary Variabel Independent Pada Recommendation

\begin{tabular}{|l|r|r|r|r|}
\hline Model & $R$ & $R$ Square & \multicolumn{1}{c|}{$\begin{array}{c}\text { Adjusted } \mathrm{R} \\
\text { Square }\end{array}$} & $\begin{array}{c}\text { Std. Error of the } \\
\text { Estimate }\end{array}$ \\
\hline 1 &, $605^{\mathrm{a}}$ &, 366 &, 360 & 1,633 \\
\hline
\end{tabular}

Predictors: (Constant), Esthetic Experience X4, Education Experience X2, Escape Experience X3, Entertainment Experience X1.

Nilai R Square sebesar 0,366 sehingga dapat diartikan bahwa variasi Recommendation dapat dijelaskan oleh variasi Entertainment Experience, Escape Experience, Education Experience dan Esthetic Experience sebesar 36,6\% dan sisanya sebesar $64,4 \%$ ditentukan atau dapat dijelaskan oleh variasi variabel lain yang tidak di teliti misalnya seperti variabel penelitian experience quality.

Tabel 4,9

Modal Summary Uji Normalitas

\begin{tabular}{|l|r|r|r|r|}
\hline Model & \multicolumn{1}{|c|}{ R } & R Square & \multicolumn{1}{c|}{$\begin{array}{c}\text { Adjusted R } \\
\text { Square }\end{array}$} & $\begin{array}{c}\text { Std. Error of the } \\
\text { Estimate }\end{array}$ \\
\hline 1 & .505 & .255 & .248 & 2,044 \\
\hline
\end{tabular}

Dapat diketahui hasil dengan menggunakan cara ini secara keseluruhan (dilihat dari nilai residual) data memiliki distribusi normal, untuk variabel $\mathrm{X}$ yaitu Tourist Experience dan Y yaitu Revisit Intention. 


\section{KESIMPULAN DAN SARAN}

Berdasarkan hasil penelitian yang telah dilakukan dari hasil pembahasan tentang Analisis tourist experience terhadap revisit intention, survei pada pengunjung objek wisata air panas se Kabupaten Garut dapat disimpulkan sebagai berikut: terdapat pengaruh antara Entertainment Experience terhadap revisit intention. Adapun pengaruhnya positif dan dalam ukuran interpretasi sedang yang menunjukkan bahwa setiap peningkatan entertainment experience akan memberikan kontribusi peningkatan terhadap revisit intention ke objek wisata air panas se Kabupaten Garut, kemudian terdapat pengaruh antara Escape Experience terhadap revisit intention. Adapun pengaruhnya positif dan dalam ukuran interpretasi sedang yang menunjukkan bahwa setiap peningkatan escape experience akan memberikan kontribusi peningkatan terhadap revisit intention ke objek wisata air panas se Kabupaten Garut. Terdapat pengaruh antara Education Experience terhadap revisit intention. Adapun pengaruhnya positif dan dalam ukuran interpretasi sedang yang menunjukkan bahwa setiap peningkatan education experience akan memberikan kontribusi peningkatan terhadap revisit intention ke objek wisata air panas se Kabupaten Garut. Dan terdapat pengaruh antara Esthetic Experience terhadap revisit intention. Adapun pengaruhnya positif dan dalam ukuran interpretasi rendah yang menunjukkan bahwa setiap peningkatan esthetic experience akan memberikan kontribusi peningkatan terhadap revisit intention ke objek wisata air panas se Kabupaten Garut.

Kemudian memberikan saran atau rekomendasi dengan harapan dapat memberikan masukan bagi kemajuan dan perkembangan pihak pengelola objek wisata air panas se Kabupaten Garut. Penelitian ini membuktikan bahwa adanya pengaruh yang signifikan antara tourist experience terhadap revisit intention wisatawan. Namun selain itu, penelitian ini juga menunjukan masih adanya masalah yang harus diperhatikan oleh pihak manajemen objek wisata air panas se Kabupaten Garut. Hal yang menjadi rekomendasi penulis adalah meningkatkan unsur kebaruan dari objek wisata air panas baik melalui aktifitas wisata dan wisatawan yang berkunjung ke objek wisata air panas. Selain itu, Rekomendasi lain yaitu ditujukan bagi pengelola objek wisata air panas se Kabupaten Garut agar dapat memberikan informasi pengunjung yang lebih jelas dengan mendata wisatawan lebih rinci agar memiliki data wisatawan yang lengkap namun tidak pula menyulitkan wisatawan.

\section{REFERENSI}

[1] J. E. Bigné, I. Sánchez, and L. Andreu, "The Role of Variety Seeking in Short and Long Run Revisit Intentions in Holiday Destinations," Int. J. Cult. Tour. Hosp. Res.,vol. 3, no. 2, pp. 103 115, 2009

[2] J. V Chen, S. Htaik, T. M. Hiele, and C. Chen, "Investigating International Tourists'Intention to Revisit Myanmar Based on Need Gratification, Flow Experience and

[3] C. Lin, "Effects Of Cuisine Experience , Psychological Wellbeing, And Self-Health Perception On The Revisit Intention Of Hot Springs Tourists," vol. 38, no. 2, pp. 243-265, 2014.

[4] M. Marinkovic, V., Senic, V., Ivkov, D., Dimitrovski, D., \& Bjelic, "The antecedents of satisfaction and revisit intentions for full-service restaurants," Mark. Intell. Plan., vol. 32, no. 3, pp. 311-327, 2014.

[5] V. a. Quintal and A. Polczynski, "Factors influencing tourists' revisit intentions," Asia Pacific J. Mark. Logist., vol. 22, no. 10, pp. 554578, 2010

[6] C. H. S. Liu and T. Lee, "Service quality and price perception of service: Influence on wordof-mouth and revisit intention," J. Air Transp. Manag., vol. 52, pp. 42-54, 2016.

[7] S. Um, K. Chon, and Y. H. Ro, "Antecedents of revisit intention," Ann. Tour. Res.,vol. 33, no. 4, pp. 1141-1158, 2006.

[8] H. Bulus and E. M. Samdi, "Discriminant Analysis of Tourist Revisit-Intention for Effective Marketing of Ecotourism Destinations in Plateau State .," vol. 12, no. 3, pp. 63-70, 2016

[9] L. Wu, K. Chen, P. Chen, and S. Cheng, "Perceived value, transaction cost, and repurchase-intention in online shopping : A relational exchange perspective," J. Bus. Res., vol. 67, no. 1, pp. 2768-2776, 2014

[10] J. E. Bigné, I. Sánchez, L. Andreu, and I. Sa, "The role of variety seeking in short and long run revisit intentions in holiday destinations," 2014

[11] S. Sanz-Blas, D. Buzova, and E. CarvajalTrujillo, "Familiarity and visit characteristics as determinants of tourists' experience at a cruise destination," Tour. Manag. Perspect., vol. 30, no. July 2018, pp. 1-10, 2019. 
[12] Y. Wang, S. H. Hsiao, Z. Yang, and N. Hajli, "The impact of sellers' social influence on the co-creation of innovation with customers and brand awareness in online communities," Ind. Mark. Manag., vol. 54, pp. 56-70, 2016.

[13] W. Tan, "Journal of Destination Marketing \& Management Repeat visitation : A study from the perspective of leisure constraint, tourist experience , destination images, and experiential familiarity," J. Destin. Mark. Manag., no. 2013, pp. 1-10, 2016.

[14] R. Daneshvary and R. K. Schwer, "The association endorsement and consumers' intention to purchase," J. Consum. Mark., vol. 17, no. 3, pp. 203-213, 2000.

[15] E. Halpenny, S. Kono, and F. Moghimehfar, "Predicting World Heritage site visitation intentions of North American park visitors," J. Hosp. Tour. Technol., vol. 9, no. 3, pp. 417-437, 2018.

[16] M. A. Jones, K. E. Reynolds, M. J. Arnold, C. B. Gabler, S. T. Gillison, and V. M. Landers, "Exploring consumers' attitude towards relationship marketing," J. Serv.Mark., vol. 29, no. 3, pp. 188-199, 2015.

[17] H. J. Song et al., "The Influence of Tourist Experience on Perceived Value and Satisfaction with Temple Stays : The Experience Economy Theory The Influence Of Tourist Experience On Perceived Value And Satisfaction With Temple Stays : The Experience Economy," no. February 2015, pp.37-41, 2014

[18] V. C. S. Yeo, S. K. Goh, and S. Rezaei, "Consumer experiences, attitude and behavioral intention toward online food delivery (OFD) services," J. Retail. Consum. Serv., vol. 35, no. July 2016, pp. 150-162, 2017.

[19] N. Alia, W. Ab, S. Kim, and S. Brown, Chapter 10 Constructing And Shaping Tourist Experiences Via Travel Blog Engagement, vol. 8. Emerald Group Publishing Limited.

[20] F. Saeed and K. G. Grunert, "Expected and experienced quality as predictors of intention to purchase four new processed beef products," $\mathrm{Br}$. Food J., vol. 116, no. 3, pp. 451-471, 2014. 